\title{
Mitral valve lesion associated with secundum atrial septal defect Analysis by real time two dimensional echocardiography
}

\author{
SEIKI NAGATA, YASUHARU NIMURA, HIROSHI SAKAKIBARA, SHINTARO BEPPU, \\ YUNG-DAE PARK, KOHEI KAWAZOE, TSUYOSHI FUJITA
}

From the National Cardiovascular Centre, Department of Medicine, Division of Cardiology, Cardiac Surgery and Research Institute, Osaka, Japan

SUMMARY Mitral valve lesions accompanying secundum atrial septal defect were examined in 120 successive patients from May 1978 to December 1980 using real time two dimensional echocardiography. The conclusions were as follows: (1) The characteristic feature of the mitral lesion accompanying secundum atrial septal defect is a dislocation of the mitral leaflet toward the left atrial side in the area of coaptation. (2) The mitral lesion is seen in about half the patients with secundum atrial septal defect. (3) It is usually seen only in the anterior leaflet, and is found near the posteromedial commissure. Lesions in other sites on the leaflet all accompany those near the posteromedial commissure. (4) The incidence, extent, and degree of the mitral valve lesion increase with age. (5) It is assumed that the mitral valve lesion in secundum atrial septal defect starts near the posteromedial commissure in the anterior leaflet, gradually deteriorates, and extends toward the anterolateral commissure. (6) It is probable that the mitral lesion results in mitral regurgitation. (7) The mitral valve lesion is similar in appearance to mitral valve prolapse caused by the floppy mitral valve, though their causative factors may be different. It is probably the reason why the mitral valve abnormality has been described as mitral valve prolapse in previous reports.

In the present study the mitral lesion was evaluated on the distance of the dislocation between both leaflets at the area of coaptation. These criteria proved useful. Because of the similarity in appearance, it may be helpful in the assessment of primary mitral valve prolapse.

It is well known that patients with secundum atrial septal defect often have mitral regurgitation. The investigation of the mechanism of such mitral regurgitation is considered to be a major clinical problem, and reports have suggested that the major cause is mitral valve prolapse. ${ }^{12}$ In general, mitral valve prolapse began to be widely discussed clinically with the appearance of echocardiography. Real time two dimensional echocardiography is an even more effective method for detecting such prolapse than M-mode echocardiography, and it is now the most reliable method for observing mitral valve lesions, including mitral valve prolapse. ${ }^{3-6}$ This paper is intended to clarify the morphology and dynamic behaviour with respect to incidence, degree, and extent of mitral valve lesions in secundum atrial septal defect using

Accepted for publication 5 October 1982 real time two dimensional echocardiography.

\section{Subjects}

The subjects were 120 cases in which technically adequate data for the evaluation were obtained from among 130 secundum atrial septal defects looked at with real time two dimensional echocardiography from May 1978 to December 1980. The subjects ranged in age from 15 to 74 , with an average of 39.8 years, and consisted of 57 men and 63 women. Cardiac catheterisation was performed in 37 of the patients and in 36 of these radical surgery for atrial septal defect was carried out.

Twenty-five healthy subjects were also examined by real time two dimensional echocardiography as controls. They ranged in age from 16 to 57, with an average of 32.7 years, and consisted of 16 men and nine women. 


\section{Methods}

\section{ECHOCARDIOGRAPHIC PROCEDURE}

Echocardiographic examinations were performed with the patient in the supine position. The echocardiograph was a Toshiba SSH-11A, real time, phased array sector scanner. The mitral valve apparatus was examined with three different long axis images, first through the posteromedial commissure, chordae tendineae, and posteromedial papillary muscle, secondly through the central part of the valve, and, thirdly, through the anterolateral commissure, chordae tendineae, and anterolateral papillary muscle.

\section{METHOD FOR EVALUATING MITRAL VALVE LESION}

Analytical view for evaluating mitral valve lesion by two dimensional echocardiography

In preliminary observations in patients with secundum atrial septal defect with mitral regurgitation an abnormal feature was often noted on the mitral valve by real time two dimensional echocardiography. This was a dislocation of the anterior and posterior mitral leaflets at the coaptation zone (Fig. 1 and 2). One of the mitral leaflets was dislocated to the left atrial side in its closed position and the dislocation was most clearly seen at the area of coaptation, and was considered to be the major lesion in the mitral valve in cases of secundum atrial septal defect with mitral regurgitation.

In the present study, analysis was performed on this joint dislocation of the mitral leaflets and its clinical significance was considered using real time two dimensional echocardiography.

\section{Grading of severity of mitral lesion}

The grade of severity of the mitral lesion was assessed by measuring the distance of the dislocation between the anterior and posterior leaflets at the area of coaptation. Distances of dislocation of $5 \mathrm{~mm}$ or less were classified as degree 1 , those of $6 \mathrm{~mm}$ to $10 \mathrm{~mm}$ as degree 2 , and those of $11 \mathrm{~mm}$ or more as degree 3 . When both leaflets were dislocated toward the left atrial side, the distance by which the area of coapta-

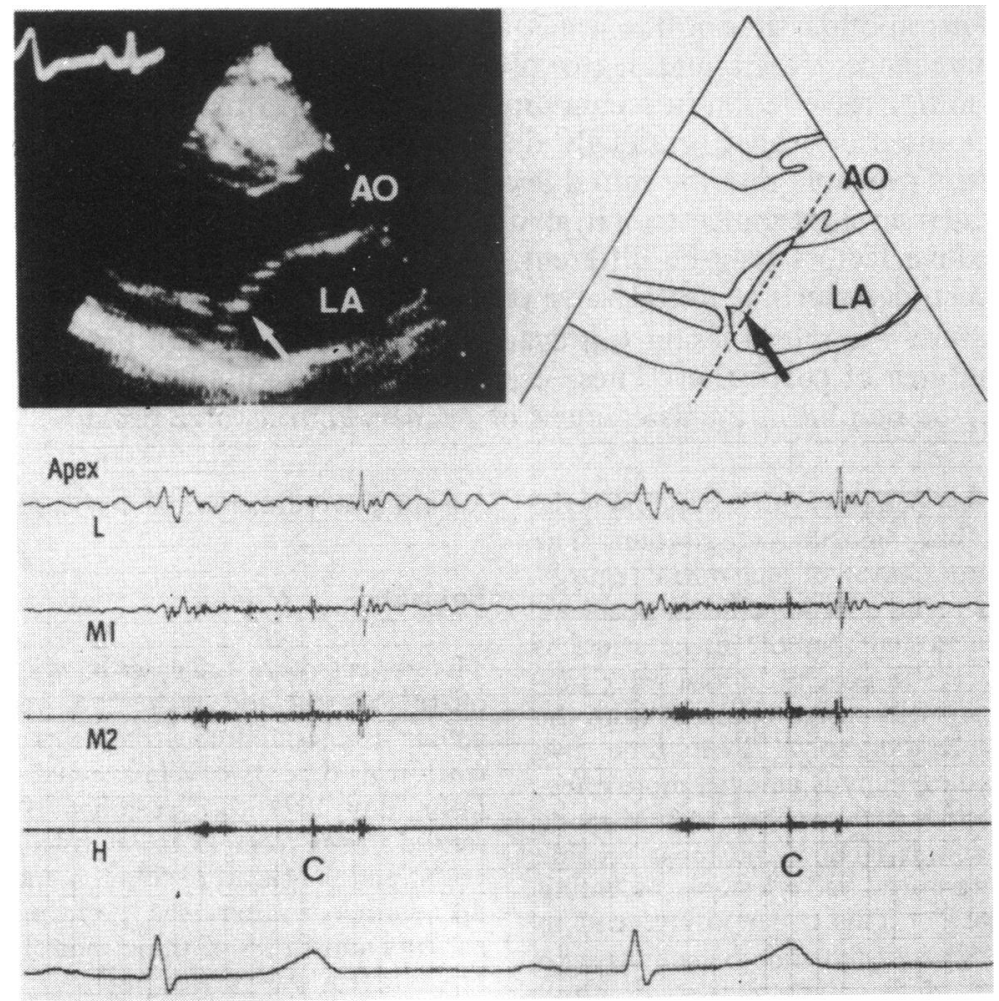

Fig. 1 Real time two dimensional echocardiogram in a case of idiopathic anterior mitral valve prolapse. In the phonocardiogram, a pansystolic regurgitant murmur and a mid-systolic click are recorded. In this case, there is dislocation between the anterior and posterior leaflets in the coaptation zone, but the anterior leaflet does not extend beyond the mitral ring. 


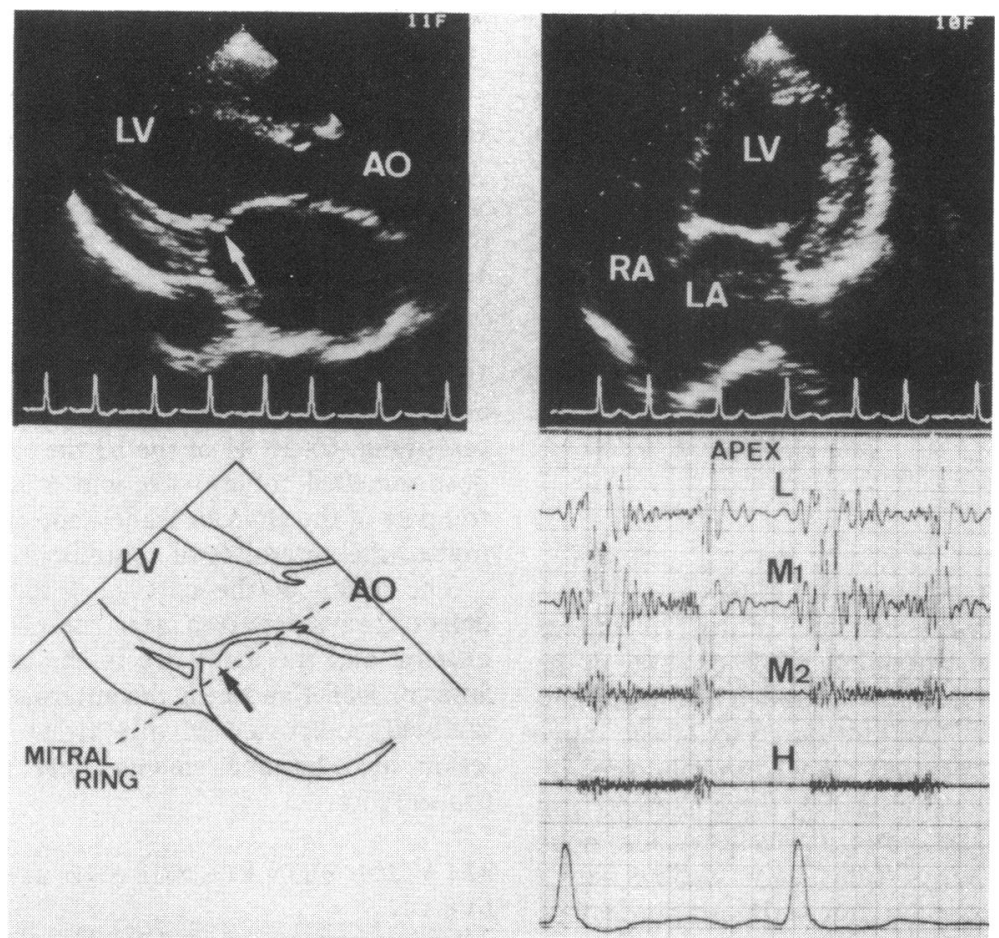

Fig. 2 Real time two dimensional echocardiogram in a case of idiopathic anterior leaflet prolapse. Apex phonocardiogram shows the pansystolic murmur. In the standard long axis view and the apical four chamber view, there is a dislocation between the anterior and posterior leaflets in the coaptation zone, but the anterior mitral leaflet does not extend beyond the mitral ring. The grade of severity of the prolapse is assessed by measuring the distance of the dislocation.

tion was dislocated across the mitral ring was measured.

For an overall assessment of the extent and degree of the lesion, the dislocation score was defined by adding these values of degree for the central part of the mitral valve and near the posteromedial and

ANTEROLATERAL COMMISSURE anterolateral commissures. For example, a dislocation score of nine indicates that there is a lesion (degree 3 ) in all three parts, that is the central part of the anterior mitral leaflet and the part near the posteromedial and the anterolateral commissures (Fig. 3).

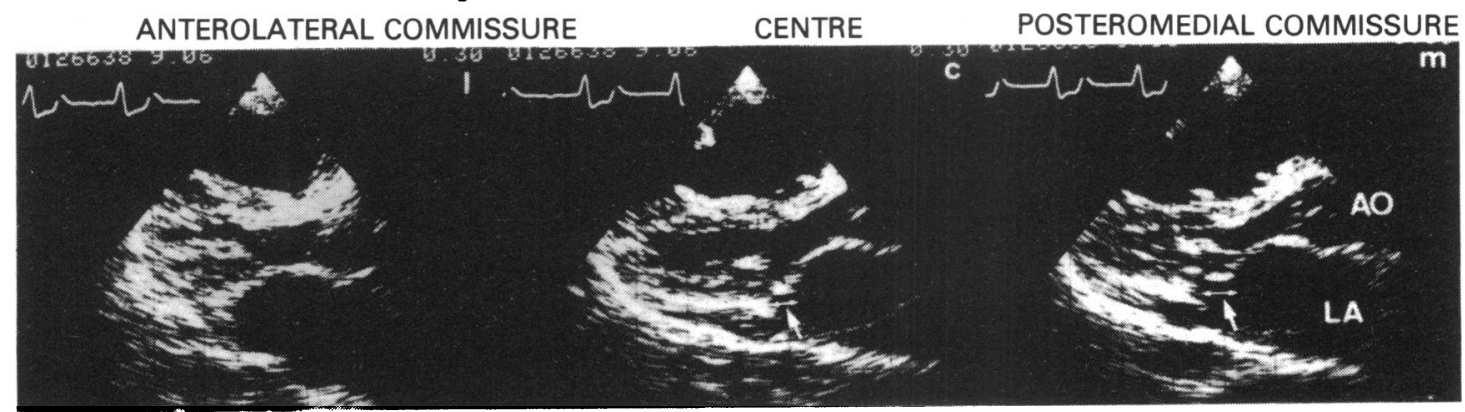

Fig. 3 Real time two dimensional echocardiogram in a case of secundum atrial septal defect with mitral valve lesion. By examining the mitral valve from three different approaches, the degree of the lesion at three positions is judged by the distance of dislocation between the anterior and posterior mitral leaflets.

The dislocation is degree 3 (dislocation of more than $10 \mathrm{~mm}$ ) near the posteromedial commissure and degree 2 (less than $10 \mathrm{~mm}$ ) at the central part of the mitral valve. There is no dislocation between the anterior and posterior mitral leaflets near the anterolateral commissure. In this case the dislocation score is 5 . 


\section{CATHETERISATION METHOD}

Thirty-seven patients underwent left and right heart catheterisation. Biplane left ventriculography was performed in the $30^{\circ}$ right anterior oblique position and in the hepatoclavicular projection. Left ventriculograms were analysed for the presence and severity of mitral regurgitation using the methods of Sellers et al. 7

\section{METHOD FOR STATISTICS}

The unpaired $t$ tests were used to make statistical comparisons. Statistical significance was at the $\mathrm{p}<0.05$ level.

\section{Results}

\section{INCIDENCE OF MITRAL VALVE LESION}

Mitral valve lesions were seen in 63 of the 120 patients with secundum atrial septal defect $(53 \%)$. Seven of the 18 cases (39\%) in the 15 to 24 age range had the lesion, as did 56 out of $102(55 \%)$ in the 25 to 74 age range (Fig. 4). Sixty of these cases showed the abnormality only in the anterior mitral leaflet, three showed it in both the anterior and posterior leaflets, and none showed it in the posterior leaflet only. Lesions with a dislocation between the anterior and posterior leaflets

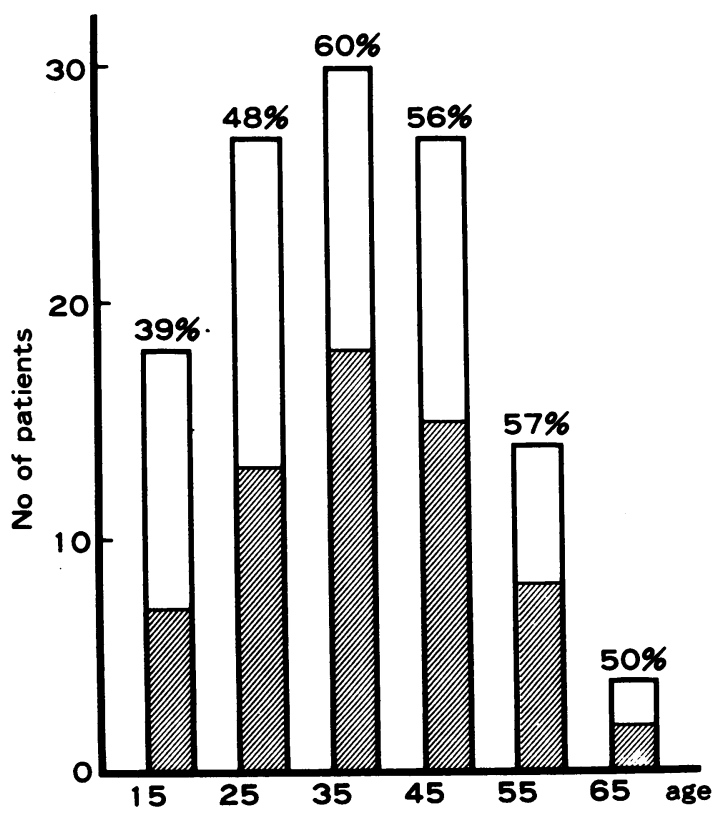

Fig. 4 The incidence of mitral valve lesions in 63 of 120 patients (53\%). Of the 63 patients, 60 patients had a lesion of the anterior mitral leaflet and three had lesions of both the anterior and posterior mitral leaflets. of $6 \mathrm{~mm}$ and more were seen in $27 \%$ of the cases (Fig. 5).

Among the 25 healthy control subjects, dislocation of both mitral leaflets was noted only in one subject, a 22 year old man. He showed premature ventricular contraction in the electrocardiogram, but no midsystolic click and no mitral regurgitant murmur on the phonocardiogram.

\section{LOCATION AND DEGREE OF LESION}

In the patients with the lesion, it was near the posteromedial commissure of the anterior leaflet in all 63 cases (Fig. 6). In 41 of the 63 the lesion was near the posteromedial commissure and extended to the central part of the anterior leaflet, and in 15 cases further toward the anterolateral commissure.

The lesion of the anterior leaflet in atrial septal defect always occurred near the posteromedial commissure and the incidence in the central part of the anterior leaflet and near the anterolateral commissure gradually decreased in this order. The size of the lesion also became smaller near the anterolateral commissure.

\section{RELATION BETWEEN AGE AND MITRAL VALVE LESION}

There was a definite relation between the lesion and the patient's age. The incidence was higher in patients in their 30's and 40's than in those in their 'teens and 20's (Fig. 4).

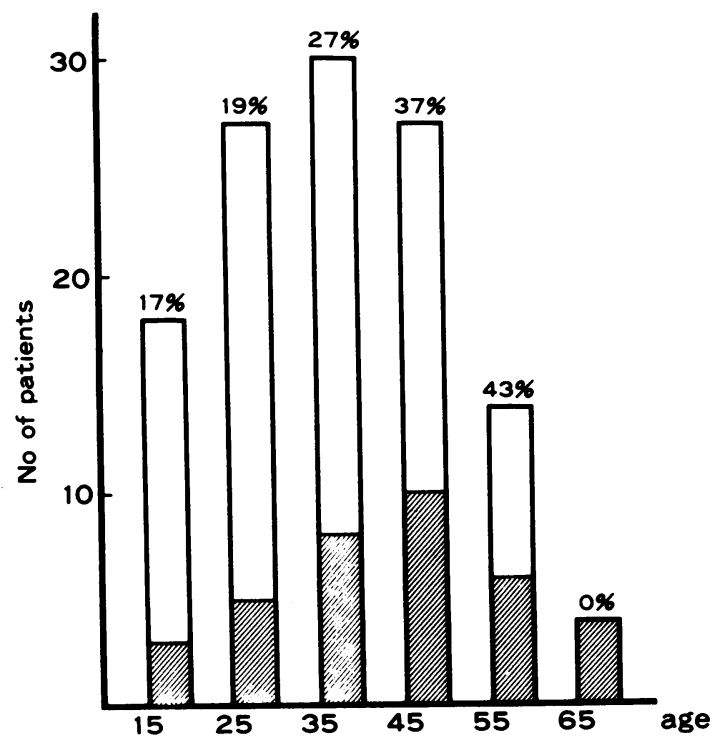

Fig. 5 The incidence of mitral valve lesions of more than $6 \mathrm{~mm}$ near the posteromedial commissure of the anterior mitral leaflet is $27 \%$. There is a tendency for the incidence of the lesion to become higher with age. 


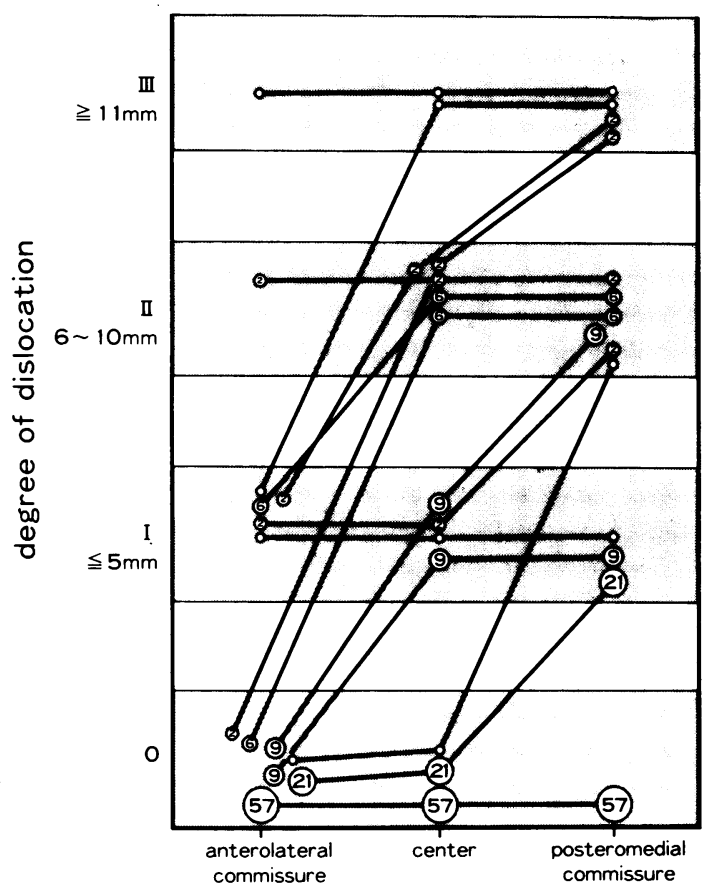

location in anterior mitral leaflet

Fig. 6 Location and extent of the mitral valve lesion. In all cases with mitral valve lesions (63 out of 63 patients, $100 \%$ ), it is located near the posteromedial commissure of the anterior mitral leaflet. In 41 of 63 patients (65\%) the lesion extends to the central part of the mitral valve, and in 15 patients (24\%) it extends almost as far as the anterolateral commissure. The grade of the lesion is high near the posteromedial commissure and becomes low as it approaches the anterolateral commissure. The number 21 , encircled, indicates that there were 21 patients with degree 1 lesion in the posteromedial commissure, and these patients had no lesion in the centre or in the anterolateral commissure of the mitral valve.

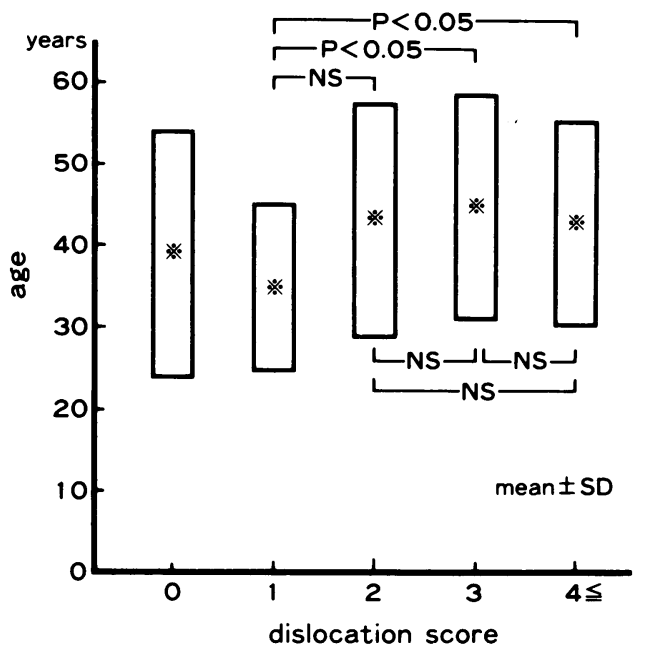

Fig. 7 Relation between the patient's age and the dislocation score. The higher the value of the dislocation score, the older the patient tends to be.

The relation between the dislocation score and age was assessed (Fig. 7). The results indicated that the higher the value of the dislocation score the older the patient. The mitral valve lesion was more extensive and more severe the older the patient. This did not mean, however, that all patients with atrial septal defect necessarily had the mitral valve lesion as they grew older. For example, the oldest of the subjects examined in the present study was 74 years, but this patient had no mitral lesion (Fig. 8).

\section{RELATION BETWEEN MITRAL VALVE LESION AND MITRAL REGURGITATION}

Mitral regurgitation was seen in 18 out of 37 patients who underwent left ventriculography (Fig. 9). Among

\section{ANTEROLATERAL COMMISSURE}

CENTRE
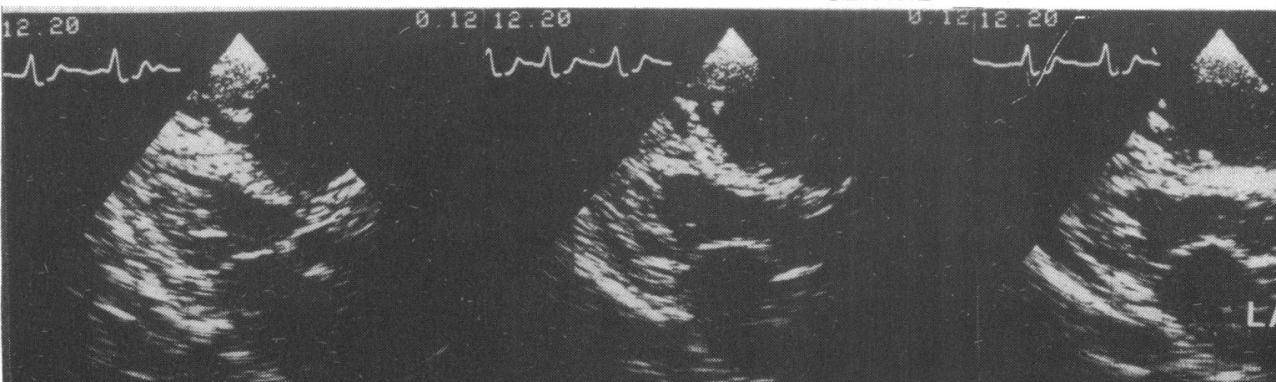

Fig. 8 Real time two dimensional echocardiograms of a 74 year old woman. From the left, real time two dimensional echocardiograms along the long axis of the heart near the anterolateral commissure, the central part, and the posteromedial commissure of the mitral valve, respectively. There is no dislocation between the anterior and the posterior leaflets. 


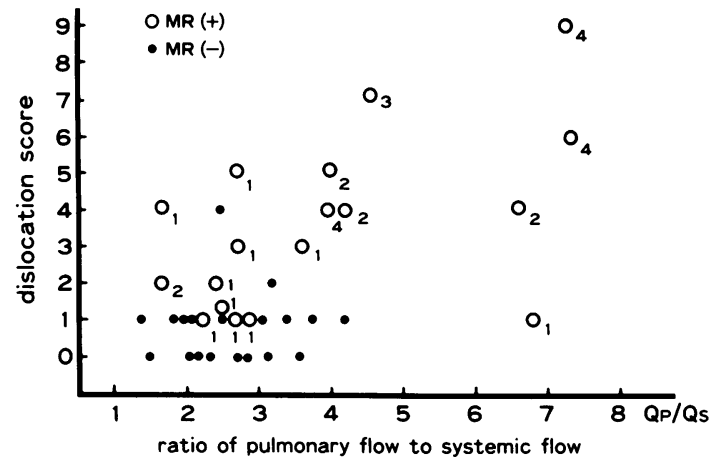

Fig. 9 Relation of mitral regurgitation (MR) assessed by angiocardiography to the degree of the lesion and the ratio of pulmonary to systemic flow volume. Of 37 patients, $18(49 \%)$ in this series had mitral regurgitation, as assessed by left ventriculography. Mitral regurgitation was seen in 13 out of 15 patients with a dislocation score of 2 or more, but not in eight patients without mitral valve lesion. Mild mitral regurgitation was seen infive out of 14 patients with dislocation score of 1 . The number next to the white circle shows the grade of mitral regurgitation assessed by left ventriculography.

these 18 patients with mitral regurgitation, 9 with a dislocation score of 4 or more had mitral regurgitation of grade 2 or higher, with a few exceptions. Only five of 14 patients with a dislocation score of 1 had mitral regurgitation of grade 1, while the other nine patients had no mitral regurgitation. None of the patients with a dislocation score of 0 had mitral regurgitation.

COURSE OF MITRAL VALVE LESION AFTER

SURGICAL CLOSURE OF ATRIAL SEPTAL DEFECT

Twenty-five patients were followed up from one month to 24 months, with an average of 8.7 months, after surgical closure of the atrial septal defect.

Of the 25 patients, 14 patients also underwent annuloplasty and shortening of the chordae tendineae. The mitral valve lesion disappeared in seven patients and remained in seven patients out of these 14 . Of the 11 patients who did not have annuloplasty and shortening of the chordae tendineae, the valve lesion disappeared in five and remained in six patients.

\section{Discussion}

INCIDENCE OF MITRAL VALVE LESION IN

SECUNDUM ATRIAL SEPTAL DEFECT

In the present study it was shown that the mitral valve lesion in secundum atrial septal defect was mainly a dislocation between the anterior and posterior mitral leaflets at the coaptation zone. The mitral lesion was seen in $53 \%$ and was $6 \mathrm{~mm}$ in size, or severe, in $27 \%$ of the patients examined. Almost the same value was reported by Kambe and coworkers 8 who investigated the incidence of prolapse of the mitral valve using real time two dimensional echocardiography. They observed a phenomenon similar to the mitral lesion in the present study, though whether it is correct to term the mitral lesion seen in atrial septal defect as mitral valve prolapse in the same sense as that in mitral valve prolapse caused by the floppy mitral valve is open to question.

These figures are higher than the reports to date which have shown incidences such as $37 \% 9$ and $17 \% .^{10}$ The authors of these papers must have seen a mitral valve lesion similar to that described in the present study. The reason for the differences between the incidence in the present study and the incidences in the other two ${ }^{910}$ is considered to be that the diagnoses in these other studies were based on left ventriculographic findings or observations during surgery. It is difficult to assess mild lesions by left ventriculography, and during operations the lack of heart beat makes evaluation difficult. One paper described this mitral valve abnormality in $90 \%$ of the cases at necropsy. ${ }^{11}$ Thus, it is certain that there is a high incidence of mitral valve abnormality in secundum atrial septal defect.

\section{MITRAL LEAFLETS IN WHICH MITRAL' VALVE} DISLOCATION IS LIKELY TO OCCUR

In the present study, the mitral valve lesion was limited to the anterior mitral leaflet in almost all patients examined. There were a few patients with the lesion involving both anterior and posterior leaflets and none with the lesion in the posterior leaflet only.

In reports to date, there have been many patients with atrial septal defect with the mitral valve abnormality mainly in the posterior leaflet, ${ }^{1}$ though it was termed mitral valve prolapse. Left ventriculography was the method used, and there were many cases where anterior leaflet prolapse was misinterpreted as posterior leaflet prolapse. ${ }^{12}$ This has also been our experience. In contrast, real time two dimensional echocardiography is a useful device to observe mitral valve abnormalities, and is a better method for assessing malorientation of the mitral leaflets than left ventriculography, even in atrial septal defect. This appears to be why the present results indicate that the mitral valve lesion occurs more often in the anterior leaflet than in the posterior leaflet, contrary to conventional concepts.

\section{LOCALISATION AND AGE DIFFERENCES OF}

MITRAL VALVE LESION

In this study the mitral valve lesion in patients with secundum atrial septal defect was usually found near the posteromedial commissure of the anterior leaflet. 
Lesions in other sites all accompanied that near the posteromedial commissure and as the lesion extended through the central part of the anterior leaflet to the vicinity of the anterolateral commissure, it became less severe in degree and less frequent in incidence. The large number of abnormalities near the posteromedial commissure has been confirmed in necropsy reports ${ }^{1113}$ and in observations during surgery. ${ }^{14}$ The present report is the first attempt to establish a non-invasive method, the results of which match these observations.

The incidence of the mitral valve lesion was found to increase with age, and previous reports have shown that mitral valve abnormalities increase with age in secundum atrial septal defect. ${ }^{81015}$ It is clearly shown in the present study that the lesion tends to extend from near the posteromedial commissure towards the anterolateral commissure with advancing age and the degree of the lesion also increases with age.

Thus, it is concluded that the mitral valve lesion in secundum atrial septal defect starts near the posteromedial commissure and often becomes gradually worse with age, extending towards the anterolateral commissure.

\section{CONSIDERATION ON PATHOGENESIS OF MITRAL VALVE LESION IN OSTIUM SECUNDUM ATRIAL SEPTAL DEFECT}

The dislocation of the mitral leaflet is apparently similar to mitral valve prolapse caused by the floppy mitral valve. It is a characteristic feature, however, of the mitral valve lesion in atrial septal defect that it is usually localised in the anterior leaflet and begins near the posteromedial commissure. This characteristic feature suggests that there may be a causative factor in atrial septal defect.

It has been well known that deformation of the left ventricular cavity is often seen in atrial septal defect, 45 and this abnormal configuration of the left ventricular cavity may cause the dislocation of the mitral valve. ${ }^{814}$ The possible explanation is that the distance between the posteromedial papillary muscle and the mitral ring is shorter in the left ventricle in atrial septal defect than in that of one of normal configuration, so that the medial half of the anterior leaflet protrudes towards the left atrial cavity and moves abnormally. ${ }^{13}$ This explanation is still speculative and remains to be confirmed in the future.

\section{GENERAL COMMENTS ON MITRAL VALVE LESION IN SECUNDUM ATRIAL SEPTAL DEFECT}

The present study showed that the mitral valve abnormality in patients with secundum atrial septal defect was mainly a dislocation of both the anterior and posterior mitral leaflets. Here, emphasis was given on the dislocation at the area of coaptation.
In the present study the diagnostic criteria were based on the findings at the coaptation zone. These criteria enabled us to obtain a systematic view of the mitral valve abnormality in atrial septal defect. The dislocation score properly matched the grade of mitral regurgitation assessed by left ventriculography. The adequacy of the diagnostic criteria is considered to be proved retrospectively by these definitive results.

The mitral valve lesion in atrial septal defect is generally similar in appearance to mitral valve prolapse resulting from the floppy mitral valve. This might be why the valve abnormality in atrial septal defect has been described as mitral valve prolapse in previous reports. As discussed earlier, however, the pathogenetic factor is possibly different in mitral valve lesions in atrial septal defect from that in primary mitral valve prolapse. It may be, therefore, controversial to term the mitral valve lesion in atrial septal defect as mitral valve prolapse, but we tentatively suggest that the mitral lesion in atrial septal defect may be mitral valve prolapse in its broader sense.

So far, mitral valve prolapse has been generally evaluated as a condition where the mitral leaflet extends beyond the mitral ring towards the left atrial cavity. ${ }^{16} 17$ There are, however, patients who are considered to have mild prolapse, and, in these, the mitral valve shows a dislocation between the anterior and posterior leaflets in the area of coaptation, though it does not extend beyond the mitral ring (Fig. 1 and 2). ${ }^{18}$ As the diagnostic criteria are based on the similarity in appearance between the mitral valve lesion and ordinary mitral valve prolapse, these criteria could be applied to evaluate ordinary mitral valve prolapse.

In the present study, there was one subject among the 25 healthy control subjects who showed a dislocation between both the mitral leaflets, using the present criteria. The incidence of abnormality in healthy subjects using the present criteria does not seem to be higher than those in previous studies ${ }^{19} 20$ using the orthodox criteria.

\section{References}

1 McDonald A, Harris A, Jefferson K, Marshall J, McDonald L. Association of prolapse of posterior cusp of mitral valve and atrial septal defect. Br Heart $\mathcal{F} 1971$; 33: 383-7.

2 Pocock WA, Barlow JB. An association between the billowing posterior mitral leaflet syndrome and congenital heart disease, particularly atrial septal defect. Am Heart $\mathcal{F}$ 1971; 81: 720-2.

3 Inoh T, Maeda K, Oda A. Diagnosis and classification of the mitral valve prolapse by the ultrasoundcardiotomography and the evaluation of the M-mode technic. $\mathcal{F}$ n Circ F 1979; 43: 305-12. 
4 Lieppe W, Scallion R, Behar VS, Kisslo JA. Twodimensional echocardiographic findings in atrial septal defect. Circulation 1977; 56: 447-56.

5 Schreiber TL, Feigenbaum H, Weyman AE. Effect of atrial septal defect repair on left ventricular geometry and degree of mitral valve prolapse. Circulation 1980; 61: 888-96.

6 Mintz GS, Kotler MN, Parry WR, Segal BL. Statistical comparison of $M$ mode and two dimensional echocardiographic diagnosis of flail mitral leaflets. Am $\mathcal{f}$ Cardiol 1980; 45: 253-9.

7 Sellers RD, Levy MJ, Amplatz K, Lillehei CW. Left retrograde cardioangiography in acquired cardiac disease. Am $\mathcal{F}$ Cardiol 1964; 14: 437-47.

8 Kambe T, Ichimiya S, Toguchi M, Hibi N, Fukui Y, Nishimura K. Cross-sectional echocardiographic study on the mitral valve prolapse associated with secundum atrial septal defect. Pre- and post-operative comparison. Fpn Circ F 1981; 45: 260-7.

9 Betriu A, Wigle ED, Felderhof $\mathrm{CH}$, McLoughlin MJ. Prolapse of the posterior leaflet of the mitral valve associated with secundum atrial defect. Am $\mathcal{F}$ Cardiol 1975; 35: 363-9.

10 Leachman RD, Cokkinos DV, Cooley DA. Association of ostium secundum atrial septal defects with mitral valve prolapse. Am $\mathcal{F}$ Cardiol 1976; 38: 167-9.

11 Okada R, Glagov S, Lev M. Relation of shunt flow and right ventricular pressure to heart valve structure in atrial septal defect. Am Heart $\mathcal{F}$ 1969; 78: 781-95.

12 Cohen MV, Shah PK, Spindola-Franco $H$. Angiographic-echocardiographic correlation in mitral valve prolapse. Am Heart $\mathcal{f}$ 1979; 97: 43-52.
13 Davies MJ. Mitral valve in secundum atrial septal defects. Br Heart F 1981; 46: 126-8.

14 Furuta S, Wanibuchi Y, Ino T, Aoki K. Etiology of mitral regurgitation in secundum atrial septal defect. $\mathcal{F} p n$ Circ F 1982; 46: 346-51.

15 Somerville J, Kaku S, Saravalli O. Prolapsed mitral cusps in atrial septal defect. An erroneous radiological interpretation. Br Heart $\mathcal{F}$ 1978; 40: 58-63.

16 Gilbert BW, Schatz RA, VonRamm OT, Behar VS, Kisslo JA. Mitral valve prolapse: two-dimensional echocardiographic and angiographic correlation. Circulation 1976; 54: 716-23.

17 Morganroth J, Jones RH, Chen CC, Naito M. Twodimensional echocardiography in mitral, aortic and tricuspid valve prolapse. Am F Cardiol 1980; 46: 1164 77.

18 Nagata S, Sakakibara H, Mikami T, et al. Idiopathic mitral valve prolapse: analysis by real-time twodimensional echocardiography. Fpn Circ $\mathcal{F}$ 1982; 46: 369-76.

19 Markiewicz W, Stoner J, London E, Hunt SA, Popp RL. Mitral valve prolapse in one hundred presumably healthy young females. Circulation 1976; 53: 464-73.

20 Gardin JM, Henry WL, Savage DD, Epstein SE. Echocardiographic evaluation of an older population without clinically apparent heart disease (abstract). Am $\mathcal{F}$ Cardiol 1977; 39: 277.

Requests for reprints to Dr Seiki Nagata, Division of Cardiology, Department of Medicine, National Cardiovascular Centre, 5-chome, Fujishirodai, Suita, Osaka 565, Japan. 